\title{
Identificação da Leptospira interrogans sorovar pomona em camundongos geneticamente selecionados, para a alta e baixa produção de anticorpos, através da técnica de imunoperoxidase em tecido renal e isolamento bacteriano em meio de Fletcher
}

\author{
Identification of Leptospira interrogans serovar pomona in mice \\ genetically selected for high and low antibody production, by means of the \\ immunoperoxidase technique in renal tissue and bacterial isolation \\ in Fletcher medium
}

\author{
Maria Cristina Santos Haanwinckel ${ }^{1,2,3}$, Juliana Semin Cavalheiro ${ }^{1,2}$ \\ e Silvio Luis de Oliveira ${ }^{1,2}$
}

\begin{abstract}
RESUMO
o presente trabalho teve por objetivo identificar a presença da Leptospira interrogans sorovar pomona em camundongos geneticamente selecionados para a alta e baixa resposta a anticorpos. Todos os animais foram submetidos ao isolamento bacteriano, imunobistoquímica (imunoperoxidase) em cortes de tecido renal e coloração através da hematoxilina-eosina. A técnica de imunoperoxidase apresentou-se pouco mais sensível em relação ao cultivo, entretanto, ambas foram bons parâmetros de identificação do agente. Presença de lesões renais mais intensas ocorreram em períodos em que houve maior número de bactérias isoladas em meio de cultivo. Camundongos da linhagem $H_{I V-A}$ conseguiram eliminar as leptospiras com maior eficiência e rapidez em relação as linhagem $L_{I V-A}$ entretanto o estudo demonstrou que ambas linhagens da seleção IV-A foram eficientes em controlar o processo infeccioso.
\end{abstract}

Palavras-chaves: Leptospira sorovar pomona. Camundongos Biozzi. Imunoperoxidase. Aspectos imunológicos.

\begin{abstract}
The present work had the objective of identifying the presence of Leptospira interrogans serovar pomona in mice that bad been genetically selected for high and low response to antibodies. All the animals were subjected to bacterial isolation, immunobistochemical analysis (immunoperoxidase) in renal tissue sections and hematoxylin-eosin staining. The immunoperoxidase technique was little more sensitive than culturing, but both were good parameters for agent identification. More severe renal lesions were present at times when there were greater numbers of bacteria isolated in culture medium. Mice of the lineage $H_{I V-A}$ were able to eliminate the Leptospira more efficiently and faster than the lineage $L_{I V-A}$ could. However, the study demonstrated that both lineages of the IV-A selection were efficient in controlling the infectious process.
\end{abstract}

Key-words: Leptospira serovar pomona. Biozzi mice. Immunoperoxidase. Immunological characteristics.

\footnotetext{
1. Departamento de Doenças Tropicais e Diagnóstico por Imagem, Faculdade de Medicina, Universidade Estadual Paulista, Botucatu-SP, 2. Departamento de Microbiologia e Imunologia, Instituto de Biociências, Universidade Estadual Paulista, Botucatu-SP, 3. Bolsista CNPq.

Apoio financeiro: Conselho Nacional de Desenvolvimento Científico (CNPq).

Endereço para correspondência: Dra ${ }^{a}$ Maria Cristina Santos Haanwinckel. Dept ${ }^{\circ}$ de Microbiologia-Imunologia/IB/UNESP, Distrito de Rubião Junior s/n, 18618-100 Botucatu-SP.

Tel: 5514 3811-6058

e-mail: crishane@ibb.unesp.br

Recebido para publicação em: 04/07/2007

Aceito em: 16/10/2007
} 
A aglutinação microscópica com antígenos vivos é 0 procedimento mais utilizado na rotina diagnóstica ${ }^{21}$. Entretanto, técnicas baseadas em detecção histológica como a imunohistoquímica dentre elas, a imunoperoxidase, vêm sendo utilizadas principalmente em pesquisas epidemiológicas.

Alguns estudos ${ }^{14}$ comparando a imunoperoxidase e 0 cultivo na detecção de leptospiras em rins, verificaram 100\% e 77,5\% de positivos respectivamente, relacionando a menor eficiência do cultivo a reação inflamatória e presença de contaminantes.

Os hamsters e cobaias são animais mais utilizados em pesquisas sobre os diversos sorovares da leptospira, entretanto, outros modelos vêm sendo utilizados.

Algumas infecções têm sido estudadas utilizando modelos experimentais para a boa (high) e má (low) resposta a anticorpos, com ênfase na resistência das linhagens $\mathrm{H}$ em infecções extracelulares $^{19}$, ou maior resistência das linhagens L contra patógenos intracelulares?

Esse estudo teve por objetivo investigar o comportamento de linhagens de camundongos selecionados geneticamente para boa ou má resposta de anticorpos (seleção IV-A) quando infectados experimentalmente com a Leptospira sorovar pomona, identificando leptospiras em tecidos renais através da técnica de imunoperoxidase e isolamento em meio de cultivo.

\section{MATERIAL E MÉTODOS}

Amostra. Foram utilizados 60 camundongos machos das linhagens high e low da seleção IV-A com quatro a oito semanas de idade infectados experimentalmente com o sorovar pomona. Controles negativos não infectados foram constituídos por 24 animais pertencentes às mesmas linhagens.

Os sacrifícios foram realizados em períodos determinados e após a colheita do sangue, os rins, foram retirados e utilizados nas técnicas histológica de hematoxilina-eosina e imunoperoxidase 0 projeto foi aprovado pelo comitê de ética experimental da Faculdade de Medicina de Botucatu (Protocolo-383/2004).

Técnica de soroaglutinação. A pesquisa de anticorpos anti-Leptospira interrogans sorovar pomona foi realizada através da técnica de aglutinação microscópica em lâmina segundo técnica de Faine ${ }^{12}$ em soros obtidos dos camundongos controle e infectados.

Isolamento. Fragmentos de rins dos animais necropsiados foram submetidos ao cultivo através de técnica de diluições seriadas $^{2022}$.

Imunoperoxidase indireta. Os cortes renais foram submetidos à reação de imunoperoxidase segundo técnica modificada de Ellis e cols ${ }^{11}$, para a pesquisa de antígenos leptospiricos do sorogrupo pomona.

A leitura das lâminas foi realizada em microscópio óptico (Leika) com ocular de 10X e objetiva de 40X e 100X (imersão) e condensador de campo claro.

Controle de especificidade. Objetivando a redução de possíveis reações inespecíficas o anticorpo foi mantido pré- incubado em suspensão de tecido renal de hamsters sadios, para que as imunoglobulinas fossem conjugadas de forma inespecífica aos determinantes antigênicos presentes no tecido renal, permanecendo livre 0 anticorpo antileptospira sorovar pomona para a reação antígeno-anticorpo. Em seguida, três áreas das lâminas destinadas aos cortes foram demarcadas com extensão aproximada de 0,5 centímetro quadrado com 0 auxílio de caneta para marcação imunohistoquímica Dakopen (DAKO Laboratories). Na primeira área demarcada foi adicionado 0 anticorpo primário ${ }^{11}$, na segunda 0 anticorpo pré-absorvido com as leptospiras formalizadas ${ }^{311} 24$ e na terceira área omitiu-se 0 anticorpo primário ${ }^{1126}$.

Técnica histológica de hematoxilia-eosina. Os fragmentos renais também foram submetidos à técnica de hematoxilina-eosina, segundo Behmer cols ${ }^{6}$.

Para comparação das técnicas de cultivo e imunoperoxidase utilizou-se a análise de concordância Kappa e teste de proporções $^{28}$. Na análise sobre a produção de anticorpos foi utilizada a prova não paramétrica de Kruskal-Wallis para amostras independentes

\section{RESULTADOS}

A analise dos títulos sorológicos presentes na Figura 1 revela que não houve diferença estatística significativa entre as linhagens geneticamente selecionadas, embora aparentemente tenham sido detectados níveis de anticorpos mais elevados na linhagem $\mathrm{H}_{\mathrm{VV}-\mathrm{A}}$ quando comparada a linhagem $\mathrm{L}_{\mathrm{INA}}$, principalmente entre 0 sétimo e o vigésimo primeiro dias pós-inoculação. A partir do vigésimo oitavo dia houve uma acentuada elevação dos títulos.

Nos cortes histológicos corados pela imunoperoxidase, a leptospira foi detectada formando massas de aglomerados filiformes de coloração amarronzada destacados do fundo azul corado pela hematoxilina (Figura 2).

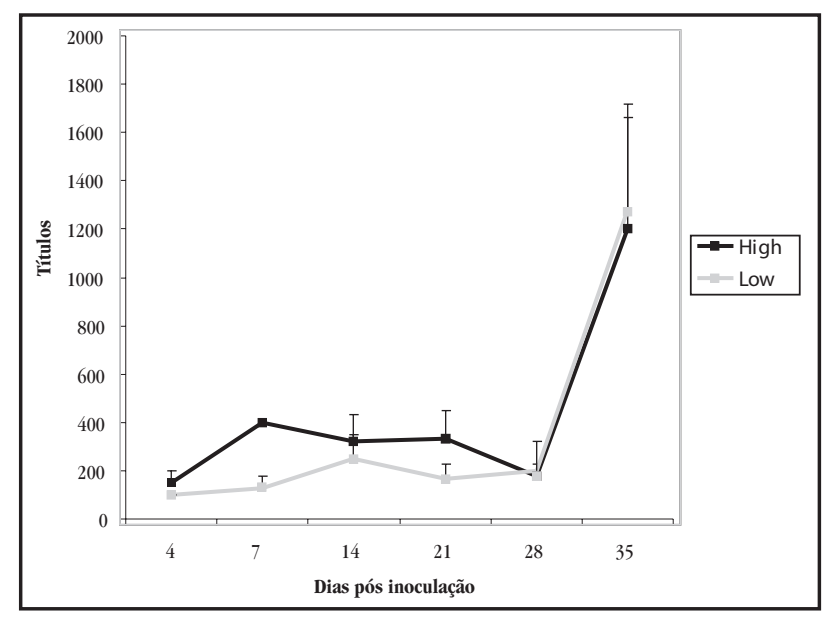

Prova não paramétrica de Kruskal-Wallis para amostras independentes.

Figura 1 - Média e desvio padrão sobre a produção de títulos sorológicos, submetidos ao teste de aglutinação microscópica frente ao antígeno de Leptospira interrogans sorovar pomona, em camundongos high e low, inoculados com $2 x 10^{7}$ leptospiras/ml. 


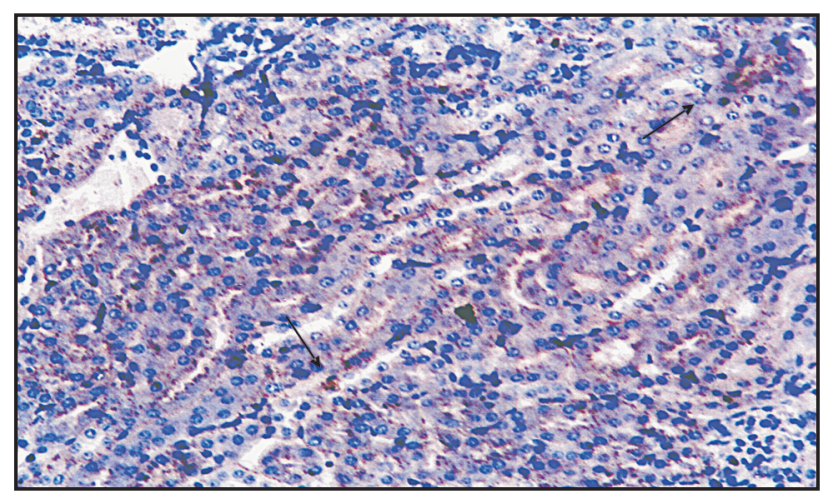

Coloração pela imunoperoxidase indireta. Aumento 40x. Microscópio Leika.

Figura 2 - Fotomicrografia de rim de camundongo high infectado com Leptospira interrogans sorovar pomona. Observar a presença de antígenos de forma dispersa ou no lúmen dos túbulos (setas).

Houve variação na intensidade de coloração principalmente a partir do $14^{\circ}$ dia pós-inoculação com menor intensidade de coloração em lâminas que apresentavam número reduzido de antígenos leptospíricos.

Comparando-se o cultivo com a imunoperoxidase houve maior número de amostras positivas nos animais da linhagem $\mathrm{H}_{\mathrm{IV}-\mathrm{A}}$ em relação à linhagem $\mathrm{L}_{\mathrm{IV}-\mathrm{A}}$ entre $04^{\circ}$ e $7^{\circ}$ dias pós-inoculação (Tabela 1). Entretanto houve diferença estatística significativa $(\mathrm{p}<0.05)$ apenas no $4^{0}$ dia pós-inoculação.Nos períodos finais os animais da linhagem $\mathrm{L}_{\mathrm{IV}-\mathrm{A}}$ passaram a apresentar maior número de positivos em relação à linhagem $\mathrm{H}_{\mathrm{IV}-\mathrm{A}}$.

Tabela 1 - Comparação de resultados entre as técnicas de visualização bacteriana e imunoperoxidase indireta em cortes frente ao cultivo bacteriano em Camundongos $H_{I V A}$ e $L_{I N A}$ infectados com o sorovar pomona. Resultados expressos em número de animais positivos por perído. (15), total de animais por período.

\begin{tabular}{lccccc}
\hline \multirow{2}{*}{ Dias/animais } & \multicolumn{2}{c}{ Imunoperoxidase } & & \multicolumn{2}{c}{ Cultivo } \\
\cline { 2 - 3 } \cline { 5 - 6 } & high & low & & high & low \\
& $(15)$ & $(15)$ & & $(15)$ & $(15)$ \\
\hline 4 & $12^{*}$ & $6^{*}$ & & $9^{*}$ & $3^{*}$ \\
7 & 12 & 9 & & 9 & 6 \\
14 & 9 & 9 & & 6 & 3 \\
21 & 3 & 6 & & - \\
28 & - & - & & - \\
35 & - & - & & - \\
*Teste para proporções. Diferenças significativas inter-linhagens $(\mathrm{HxL}) \mathrm{p}<0,05$
\end{tabular}

Foi possível observar boa concordância entre as técnicas de identificação da leptospira na linhagem $\mathrm{H}_{\mathrm{IV}-\mathrm{A}}$ apenas no $14^{\circ}$ dia pósinoculação (Tabela 2) o mesmo ocorrendo com a linhagem $\mathrm{L}_{\mathrm{IV}-\mathrm{A}}$ no $7^{0}$ dia (Tabela 3). Em outros períodos as concordâncias foram consideradas moderadas (Tabela 4 e 5), ou fracas (Tabela 6).

A intensidade e o grau de alterações celulares observadas nos tecidos dos camundongos infectados com o sorovar pomona através da coloração de hematoxilina e eosina, se caracterizaram por processo degenerativo a partir do quarto dia pós-inoculação, estendendo-se até o vigésimo oitavo dia de infecção, mesmo em presença de resultados negativos no isolamento em meio de cultivo, variando, entretanto, em diferenças de intensidade
Tabela 2 - Concordância entre as técnicas de imunoperoxidase indireta em cortes (IP) e cultivo bacteriano em Camundongos $H_{I V-A}$ no $14^{\circ}$ dia pós-inoculação.

\begin{tabular}{lrrr}
\hline \multirow{2}{*}{ IP } & \multicolumn{2}{c}{ Cultivo } & \\
\cline { 2 - 3 } & + & - & Total \\
\hline+ & 6 & 3 & 9 \\
- & 0 & 6 & 6 \\
\hline Total & 6 & 9 & 15 \\
\hline
\end{tabular}

IP: Teste Kappa= 0,62 [0,22;1,00], boa concordância.

Tabela 3 - Concordância entre as técnicas de imunoperoxidase indireta em cortes (IP) e cultivo bacteriano em Camundongos $L_{I V-A}$ no $7^{\circ}$ dia pós-inoculação.

\begin{tabular}{lrrr}
\hline & \multicolumn{2}{c}{ Cultivo } & \\
\cline { 2 - 3 } IP & + & - & Total \\
\hline+ & 6 & 3 & 9 \\
- & 0 & 6 & 6 \\
\hline Total & 6 & 9 & 15 \\
\hline
\end{tabular}

IP: Teste Kappa= 0,62 [0,22;1,00], boa concordância.

Tabela 4 - Concordância entre as técnicas de imunoperoxidase indireta em cortes (IP) e cultivo bacteriano em Camundongos $H_{I V-A}$ no $4^{\circ}$ dia pós-inoculação.

\begin{tabular}{lrrr}
\hline & \multicolumn{2}{c}{ Cultivo } & \\
\cline { 2 - 3 } IP & + & - & Total \\
\hline+ & 9 & 3 & 12 \\
- & 0 & 3 & 3 \\
\hline Total & 9 & 6 & 15 \\
\hline
\end{tabular}

Teste Kappa $=0,54[0,08 ; 1,00]$, concordância moderada.

Tabela 5 - Concordância entre as técnicas de imunoperoxidase indireta em cortes (IP) e cultivo bacteriano em Camundongos $L_{I V-A}$ no $4^{-}$dia pós-inoculação.

\begin{tabular}{lrrr}
\hline & \multicolumn{2}{c}{ Cultivo } & \\
\cline { 2 - 3 } IP & + & - & Total \\
\hline+ & 3 & 3 & 6 \\
- & 0 & 9 & 9 \\
\hline Total & 3 & 12 & 15
\end{tabular}

Teste Kappa $=0,54[0,08 ; 1,00]$, concordância moderada.

Tabela 6 - Concordância entre as técnicas de imunoperoxidase indireta em cortes (IP) e cultivo bacteriano em Camundongos $L_{N V A}$ no $14^{\circ}$ dia pós-inoculação.

\begin{tabular}{lrrrr}
\hline & \multicolumn{2}{c}{ Cultivo } & \\
\cline { 2 - 3 } IP & + & - & Total \\
\hline+ & 3 & 6 & 9 \\
- & 0 & 6 & 6 \\
\hline Total & 3 & 12 & 15
\end{tabular}

Teste Kappa = 0,28 [0,0;0,72], fraca concordância.

das lesões presentes. Entre o quarto e o sétimo dia pósinoculação foram observadas algumas áreas de degeneração hidrópica em presença de infiltrados inflamatórios, sobretudo polimorfonucleares principalmente próximos a vasos sanguíneos. Entre o quarto e o décimo quarto dia, foi observada com mais intensidade nefrite intersticial caracterizada por acúmulo de células mononucleares e entre o quarto e o sétimo dia pósinoculação as alterações inflamatórias aparentemente foram mais freqüientes nos animais das linhagens $\mathrm{H}_{\mathrm{IV}-\mathrm{A}}$. Entretanto, nos animais maus respondedores a presença de lesões se 
estendeu até o vigésimo oitavo dia comparando-se aos animais bons respondedores. Nenhum camundongo controle negativo apresentou quaisquer alterações histopatológicas.

\section{DISCUSSÃO}

Linhagens de camundongos selecionadas quanto à diferenciação na resposta humoral podem apresentar variáveis graus de resposta antigênica frente a antígenos de multiplicação intracelular e/ou extracelular.

Quanto à produção de anticorpos contra o sorovar pomona nas linhagens $\mathrm{H}_{\mathrm{IV}-\mathrm{A}}$ e $\mathrm{L}_{\mathrm{IV}-\mathrm{A}}$, não houve diferenças significativas, apesar dos animais $\mathrm{H}_{\mathrm{IV}-\mathrm{A}}$ produzirem mais anticorpos entre os períodos de 7 a 21 dias. Esses resultados são parcialmente discordantes de Marinho cols ${ }^{18}$. Estudando a resposta imune contra o sorovar icterohaemorrhagiae, no qual, a linhagem $\mathrm{H}_{\mathrm{IV}-\mathrm{A}}$ produziu resposta estatisticamente significante em relação à linhagem $\mathrm{L}_{\mathrm{IV}-\mathrm{A}}$, mantendo o efeito multiespecífico normalmente observado nessas linhagens.

Entretanto, são concordantes com outros experimentos ${ }^{19}$ que não observaram diferenças significativas na produção de anticorpos entre as linhagens da seleção I, quando infectadas com a Klebsiella pneumoniae.

Durante o processo infeccioso a formação de células fagocitárias e anticorpos opsonizantes são importantes no controle da enfermidade, dificultando a permanência e adaptação das leptospiras no hospedeiro. No presente estudo, foi observado que a formação de anticorpos aglutinantes ocorreu de forma aparentemente semelhante entre as duas linhagens, embora tenham sido observados valores discretamente mais elevados entre os animais da linhagem high em relação a low, determinando resposta imune multiespecífica.

A presença de imunoglobulinas provavelmente reduziu a capacidade das leptospiras em permanecer de forma viável em tecidos e órgãos, visto por resultado presente nos cultivos, concordantes com trabalhos observando a produção de anticorpos homólogos IgG contra a Leptospira interrogans sorovar copenhageni $e$ saprófita isola sacra $1^{5}$.

Camundongos da linhagem $\mathrm{H}_{\mathrm{IV}-\mathrm{A}}$ conseguiram eliminar as leptospiras com maior eficiência e rapidez em relação as linhagem $\mathrm{L}_{\mathrm{IV}-\mathrm{A}}$, tal fato pode estar associado à presença de complexos imunes e posterior formação de anticorpos circulantes ${ }^{1}$.

Com relação a imunoperoxidase, a menor intensidade de coloração em algumas amostras pode estar relacionada à distribuição ao acaso das leptospiras nos tecidos fixados, como também observado por Taylor ${ }^{26}$ e Ellis cols ${ }^{11}$, ou a mecanismos de resistência dessas linhagens.

0 controle das reações inespecíficas foi eficiente em confirmar a especificidade do anticorpo primário. Resultados também verificados por outros estudos 3112527

Analisando os resultados obtidos parece ter havido maior eficiência da técnica imunohistoquímica fato que pode estar relacionado a dificuldades inerentes ao isolamento, como sensibilidade das leptospiras em meio de cultivo, ou quantidades ineficientes do agente fator que pôde ser observado em outros estudos $^{8}$ analisando técnicas imunológicas e o cultivo na identificação da Leptospira sorovar hardjo, como também em trabalhos comparando a imunohistoquímica com o cultivo na identificação da leptospira em tecidos renais de suínos e hamsters respectivamente $\mathrm{e}^{1423}$.

Menor número de amostras positivas em fragmentos de tecidos renais dos camundongos $\mathrm{L}_{\mathrm{IV}-\mathrm{A}}$ em relação à linhagem $\mathrm{H}_{\mathrm{IV}-\mathrm{A}}$, pode pressupor que mecanismos relacionados ao metabolismo acelerado de macrófagos na linhagem $\mathrm{L}_{\mathrm{IV}-\mathrm{A}}$ tenha favorecido a eliminação inicial mais eficiente da leptospira, entretanto pode também indicar que o rápido metabolismo possa impedir que macrófagos exibam determinantes antigênicos de forma adequada, resultando em resposta imune humoral menos eficiente, pelo menos no início do processo infeccioso e são dados concordantes com outros estudos ${ }^{271315}$.

Em estudos utilizando o sorovar icterohaemorrhagiae, camundongos $\mathrm{L}_{\mathrm{IV}-\mathrm{A}}$ apresentaram-se mais resistentes à infecção com total eliminação do parasita a partir do $14^{\circ}$ dia de infecção no fígado e rins, enquanto animais $\mathrm{H}_{\mathrm{IV}-\mathrm{A}}$ apresentaram recuperação nesses órgãos até $035^{\circ} \mathrm{dia}^{17}$.

Alguns estudos sugerem que embora possam estar aparentemente saudáveis, os camundongos são susceptíveis a colonização de alguns tipos de leptospiras, sendo que a capacidade de provocar lesões em tecidos é dependente de fatores ligados à adaptação dos microrganismos aos tecidos do hospedeiro ${ }^{16}$.

As alterações degenerativas apresentadas pelos animais infectados foram concordantes com estudos ${ }^{4}{ }^{10}$ que referem proliferação de células inflamatórias principalmente nos períodos inicias da infecção.

A intensidade de lesões inflamatórias presentes nos animais $\mathrm{H}_{\mathrm{IV}-\mathrm{A}}$ coincide com a dificuldade inicial desses animais em processar e eliminar o agente infeccioso mais rapidamente em relação as linhagens $\mathrm{L}_{\mathrm{IV}-\mathrm{A}}$ como foi observado na recuperação, pois a presença da leptospira e infiltrados inflamatórios no tecidos pode contribuir para o agravamento das lesões, fato também observado por Chen'.

0 estudo demonstrou que as linhagens da seleção IV-A foram eficientes em controlar o processo infeccioso, e parecem se comportar de forma diferenciada quando expostas aos diversos sorovares da Leptospira.

Os resultados comparados a trabalhos com outros sorovares demonstraram restrições na modificação de um caráter imunológico geneticamente selecionado, por um agente externo e não específico.

Camundongos da linhagem para a boa $\left(\mathrm{H}_{\mathrm{IV}-\mathrm{A}}\right)$ ou má $\left(\mathrm{L}_{\mathrm{IV}-\mathrm{A}}\right)$ resposta a anticorpos, podem ser úteis na investigação à cerca de mecanismos adaptativos dos sorovares aos diferentes hospedeiros, sendo que o reconhecimento dos hospedeiros de manutenção ou acidentais em relação a um sorovar caracteriza importante pesquisa epidemiológica quanto ao potencial infectante de determinadas espécies animais e do homem. 


\section{AGRADECIMENTOS}

À Profa. Jane Megid e ao Prof. Hélio Langoni, do Departamento de Higiene Veterinária e Saúde Pública da Faculdade de Medicina Veterinária e Zootecnia da Universidade Estadual Paulista, Botucatu, SP. Ao Prof. Silvio Arruda Vasconcellos e a Bióloga Zenaíde Maria de Moraes, do Laboratório de Zoonoses Bacterianas do Departamento de Higiene Veterinária e Saúde Animal da Faculdade de Medicina Veterinária e Zootecnia da Universidade de São Paulo, São Paulo, SP.

\section{REFERÊNCIAS}

1. Adler B, Faine S. Serological and protective-antibody response of rabbits to leptospiral antigens. Journal of Medical Microbiology 11: 401-409, 1978.

2. Adorini L, Doria G. Defective antigen presentation by macrophages from mice genetically selected for low antibody response. European Journal of Immunology 11: 984-989, 1981.

3. Alves JA, Vasconcellos SA, Camargo CRA, Macedo NA, Morais ZM, Nurmberger Junior, R, Pinheiro SR, Ferreira Neto, JS. Influência da estimulação inespecífica com o BCG sobre a susceptibilidade do hamster à infecção experimental por Leptospira interrogans sorovar pomona. Brazilian Journal of Veterinary Research and Animal Science 29: 193-199, 1992

4. Alves VAF, Yasuda PH, Yamashiro EH, Santos RTM, Yamamoto IV, Brito T. An immunohiostochemic assay to localize Leptospires in tissue specimes. Revista do Instituto de Medicina Tropical de São Paulo 28:170-173, 1986.

5. Banfi E, Cinco M, Bellini M, Soranzo MS. The role antibodies and serum complement in the interaction between macrophages and leptospires. Journal of General Microbiology 128: 813-816, 1982.

6. Behmer OA, Tolosa EMC, Freitas Neto AG. Manual de técnicas para histologia normal e patológica, Edart Livraria e Editora Ltda, São Paulo, 1976.

7. Biozzi G, Mouton D, Stiffel C, Bouthillier Y. A major role of the macrophage in quantitative genetic regulation of immunoresponsiveness and antiinfectious immunity. Advances in Immunology 36: 189-233, 1984.

8. Bolin M, Zuerner RL, Trueba G. Comparation of three techiques to detect Leptospira interrogans serovar hardjo type Hardjo-bovis in bovine urine. American Journal of Veterinary Research 50: 1001-1003, 1989.

9. Chen A. Interleukin-1 receptor antagonist modulates the progression of a spontaneously ocorring IgA nephropathy in mice. American Journal of Kidney Diseases 30: 693-702, 1997.

10. De BN, Chatterjee A, Bidyanta J, Deb SK, Sen GP. Studies on leptospiral abortion in cattle. Indian Journal of Animal Health 22: 143-145, 1983.

11. Ellis T. Robertson GM, Huston L, Kirby M. Detection of leptospires in tissue using an immunoperoxidase staining procedure. Australian Veterinary Journal 68: 364-367, 1983

12. Faine $S$. Guidelines for the control of leptospirosis. Word Health Organization, Geneva, p. 82-83, 1982.
13. Gennari M, Boutothillier Y, Ibanez OM, Ferreira VC, Mevel JC, Reis MH, Paitti RM, Ribeiro OG, Biozzi G. Effect of silica on the genetic regulation of antibody responsiveness. Annales de L'institut Pasteur - Immunology 138: 359-370, 1987.

14. Haanwinckel MCS, Megid J, Souza C. Avaliação da prova de imunoperoxidase como recurso diagnóstico na leptospirose animal. Arquivos do Instituto Biológico 71: 293-301, 2004

15. Ibanez OM, Mouton D, Oliveira SL, Ribeiro Filho OG, Piatti RM, Sant'Anna OA, Massa S, Biozzi G, Siqueira M. Polygenic control of quantitative antibody responsiveness: restrictions of the multispecific effect related to the selection antigen. Immunogenetics 28: 6-12, 1988.

16. Kemers F, Szeky A. Leptospira sejroe infection of albino mice in Hungary (Erradication of Leptospires from the infected mouse stocks). Zentralblatt für bakteriologie, parasitenkunde, infektionskrankheiten und hygiene reihe $\mathrm{B}$ - Hygiene, prãventive medizin 13: 591-600, 1966.

17. Marinho M. Resposta imune à infecção por Leptospira interrogans sorovar icterohaemorrhagiae em linhagens de camundongos geneticamente selecionados. Tese de doutorado, Universidade Estadual Paulista, Botucatu, SP, 2000.

18. Marinho M, Langoni H, Oliveira SL, Carreira R, Perri SHV, Luvizoto MC. Resposta humoral, recuperação bacteriana e lesões histológicas em camundongos em geneticamente selecionados para bons e maus respondedores de anticorpos e balb/c, frente à infecção por Leptospira interrogans sorovar icterohaemorrhagiae. Pesquisa Veterinária Brasileira 23: 5-12, 2003.

19. Mouton D, Parant M, Meyel JC, Parant F. Dose-dependent efficacy of vaccination against $\mathrm{K}$ pneumoniae in high and low antibody responder lines of mice. Immunology Letters 14: 335-339, 1987.

20. Passos C, Vasconcellos SA, Ito FO, Yasuda PH, Nürmberger Jr R. Isolamento de Leptospiras a partir do tecido renal de hamsters experimentalmente infectados com L. interrogans sorotipo pomona: Emprego das técnicas de Pipeta Pasteur e das diluições seriadas em meio de cultura de Fletcher tratado com 5-fluoruracil ou sulfato de neomicina. Revista da Faculdade de Medicina Veterinária e Zootecnia da Universidade de São Paulo 25: 221-235, 1988.

21. Pinto AA, Santa Rosa CA, Sadatsune T, Fkeury G C. Comparative study between complement fixation and microscopic agglutination tests for leptospiral diagnosis. Revista do Instituto de Medicina Tropical de São Paulo 16: 28-31, 1974.

22. Rosa CAS. Diagnóstico Laboratorial das Leptospiroses. Review Microbiology 1: $97-109,1970$

23. Scanziani E, Luini M, Fabbi M, Pizzocaro P. Comparation between specific immunoperoxidase staining and bacteriological culture in the diagnosis of renal leptospirosis of pigs. Research in Veterinary Science 50: 229-232, 1991.

24. Schalm OW, Jain NC, Carrol EJ. Hematologic techinics. In: Jain NC (ed) Schalm's Veterinary Hematology, Lea Febiger, Philadelphia, p. 21-86, 1986.

25. Sternberger LA, Hardy PH Jr, Circulis JJ, Meyer HG. The unlabeled antibody enzyme method of immunohistochemistry. Journal of Histochemistry and Cytochemistry 18: 315-333, 1970.

26. Taylor CR. Immunoperoxidase techniques: Practical and theoretical aspects. Archives of Pathology and Laboratory Medicine 102: 113-121, 1978.

27. Tripathy DN, Hanson LE. Immunoperoxidase staining of leptospires. Applied Microbiology 27: 268-269, 1974.

28. Zar JH. Bioestatistical analysis, $3^{\text {th }}$ edition, Prentice Hall, Upper Saddle River, New Jersey, 1996 